\title{
Desenvolvimento de mudas de eucalipto submetidas à fertirrigação com água residuária da suinocultura
}

Uma das alternativas que se tem apontado para a resolução dos problemas causados pela disposição inadequada de resíduos agroindustriais é a sua reutilização na agricultura. Todavia, o uso incorreto pode causar efeitos deletérios ao solo, aos recursos hídricos e ser fator de risco a saúde animal e humana. Assim, com este trabalho, objetivou-se estudar o reuso da água residuária da suinocultura (ARS) no desenvolvimento de mudas de eucalipto. Para isso, foram produzidas mudas da variedade Eucalyptus urophylla, as quais foram transplantadas para vasos e submetidas a fertirrigações com ARS, após tratamento preliminar, de modo a se fornecer $100 \%$ e $200 \%$ da dose nitrogênio recomendada para o eucalipto, sem adubação mineral complementar e com adubação mineral complementar. A adubação mineral complementar foi calculada subtraindo-se a quantidade de fósforo e potássio aportada pelas diferentes doses de ARS daqueles valores recomendados para a cultura. Os resultados permitiram concluir que a fertirrigação com ARS possibilitou o suprimento das demandas nutricionais, proporcionando mudas com bom desenvolvimento e metabolismo, apresentando maiores comprimentos, diâmetros do coleto e índice de qualidade; considerando-se os aspecto econômicos e ambientais, a fertirrigação com ARS fornecendo $200 \%$ da dose de nitrogênio, sem complementação da adubação, passa a ser uma recomendação técnica e ambientalmente adequada.

Palavras-chave: Reuso; Efluente; Adubação Orgânica.

\section{Eucalyptus seedlings development submitted to fertirrigation with swine wastewater}

\begin{abstract}
One of the alternatives that has been pointed out to solve the problems caused by the inadequate disposal of agroindustrial wastes is its reuse in agriculture. However, incorrect use may cause deleterious effects on soil, water resources and be a risk factor for animal and human health. Thus, this study aimed to study the reuse of swine wastewater (SW) in the development of eucalyptus seedlings. For this, seedlings of the variety Eucalyptus urophylla were produced, transplanted into potted plants and subjected to fertigated WS, after a preliminary treatment, in order to provide $100 \%$ and $200 \%$ of the recommended fertilizer rate for eucalyptus without additional mineral fertilizer and with complementary mineral fertilization. The supplemental mineral fertilization was calculated by subtracting the amount of phosphorus and potassium contributed by the different WS doses from those recommended values for the crop. The results allowed to conclude that WS fertigation allowed the supply of nutritional demands, providing seedlings with good development and metabolism, presenting higher lengths, collar diameters and quality index; considering the economic and environmental aspects, the WS fertigation supplying $200 \%$ of the nitrogen dose, without completing the fertilization, becomes a technical and environmentally adequate recommendation.
\end{abstract}

Keywords: Reuse; Effluent; Organic Fertilization

Topic: Desenvolvimento, Sustentabilidade e Meio Ambiente

Reviewed anonymously in the process of blind peer
Received: 10/08/2018

Approved: 24/09/2018
José Antonio Rodrigues de Souza (iD Instituto Federal Goiano, Brasil http://lattes.cnpq.br/1637300776838940 http://orcid.org/0000-0003-3024-9424 jose.antonio@ifgoiano.edu.br

Débora Astoni Moreira (iD

Instituto Federal Goiano, Brasil

http://lattes.cnpq.br/0892554192927049 http://orcid.org/0000-0002-8658-1269

debora.astoni@ifgoiano.edu.br

Éllen Lemes Silva (iD

Instituto Federal Goiano, Brasil

http://lattes.cnpq.br/2020996967548069

http://orcid.org/0000-0001-5649-5055

ellen cbba@hotmail.com

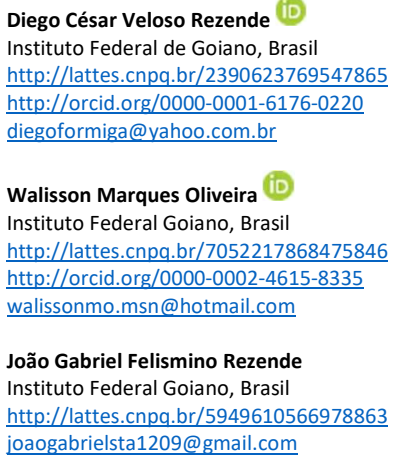

Wesley Anderson Siqueira Ribeiro Instituto Federal Goiano, Brasil http://lattes.cnpq.br/4063527816946300 http://orcid.org/0000-0003-4056-9798 wesleyk13anderson@hotmail.com
Referencing this:

SOUZA, J. A. R.; MOREIRA, D. A.; SILVA, É. L.; REZENDE, D. C. V.; OLIVEIRA, W. M.; REZENDE, J. G. F.; RIBEIRO, W. A. S.

Desenvolvimento de mudas de eucalipto submetidas à fertirrigação com água residuária da suinocultura. Revista Ibero Americana de Ciências Ambientais, v.9, n.7, p.280-288, 2018. DOI:

http://doi.org/10.6008/CBPC2179-6858.2018.007.0026 


\section{INTRODUÇÃO}

O elevado volume de efluentes gerados pela suinocultura tem se tornando fonte de grande preocupação, principalmente devido aos impactos causados pela disposição inadequada, passando a ser fonte de impactos negativos ao meio ambiente e fator de risco para a saúde animal e humana (SOUZA et al., 2013). Assim $O$ aproveitamento de efluentes na agricultura tem surgido como uma alternativa para controle da poluição das águas superficiais e subterrâneas, além da disponibilização de água e fertilizantes para as culturas, ciclagem de nutrientes e aumento na produção agrícola, reduzindo os custos de produção e melhorando as características físicas, químicas e microbiológicas do solo (MATOS, 2016).

Contudo, o uso sem critérios agronômicos e ambientais da fertirrigação com ARS pode causar problemas de infiltração da água no solo, contaminação do solo e da água, além de trazer toxicidade às plantas (ERTHAL et al., 2010). Neste sentido, a taxa de aplicação deve ser baseada no nutriente que estiver em maior concentração relativa e na dose de nutrientes recomendada para as culturas agrícolas, pois caso esses níveis sejam suplantados, podem comprometer a produtividade da cultura, além de provocar poluição do solo e das águas (MATOS, 2016).

Segundo Batista et al. (2014) a reutilização de águas residuária da suinocultura na fertirrigação de mudas de eucalipto pode se tornar uma alternativa muito promissora, em razão desta espécie apresentar grande demanda doméstica e internacional, devido à sua importância no setor florestal brasileiro. Assim, diante do exposto, com este trabalho objetivou-se estudar o desenvolvimento de mudas de Eucalyptus urophulla, quando submetidos à fertirrigação com água residuária de suinocultura.

\section{METODOLOGIA}

O trabalho foi conduzido no Instituto Federal Goiano - Campus Urutaí, em Urutaí/GO, localizado a $17^{\circ} 29^{\prime} 6^{\prime \prime} \mathrm{S}, 48^{\circ} 12^{\prime} 27^{\prime \prime} \mathrm{O}$ e altitude de $712 \mathrm{~m}$. Segundo a classificação de Köppen, o clima da região é do tipo Cwa, caracterizado como úmido tropical com inverno seco e verão chuvoso, com precipitação e temperatura médias, anuais, de $2000 \mathrm{~mm}$ e $28^{\circ} \mathrm{C}$, e o solo da região é classificado como Latossolo vermelho amarelo (SILVA, 2015).

Para condução dos ensaios experimentais, sementes de eucalipto da variedade Eucalyptus urophylla foram coletadas em área de cultivo comercial e semeadas em tubetes com capacidade volumétrica de 55 $\mathrm{cm}^{3}$, preenchidos com substrato composto por esterco humificado e solo, na proporção 1:1, colocando-se, em média, cinco sementes.

A fim de proteger as mudas, em sua fase inicial, contra o ataque de formigas e insetos, competições com plantas daninhas, impactos das gotas de irrigação e intempéries climáticas, os tubetes conduzidos para o interior de uma casa de vegetação, foram mantidos suspensos a 0,90 m do solo, apoiados em telas plásticas com malha quadriculada, e sombreados durante um período de 10 dias (sombrite 50\%).

Após germinação, foram realizados desbaste das plântulas excedentes, escolhendo-se a mais vigorosa e central em cada tubete e, após formação de três pares de folhas (aproximadamente 75 dias após 
a semeadura), conforme recomendado por Rocha et al. (2013), foram transplantadas em vasos plásticos com capacidade volumétrica de $0,012 \mathrm{~m}^{3}$, preenchidos com Latossolo Vermelho Amarelo. Durante o período de produção de mudas, foram realizadas irrigações por microaspersão, sempre que necessário.

O solo utilizado no preenchimento dos vasos foi previamente seco ao ar, destorroado, passado em peneira de 0,05 $\mathrm{mm}$ de malha e, após análise química, submetido à calagem com adição de calcário dolomítico, de acordo com as recomendações apresentadas por CFSEMG (1999). A fim de se constituir um perfil homogêneo e se obter a massa específica próxima à do solo original, o preenchimento do vaso foi realizado em camadas de aproximadamente 0,10 $\mathrm{m}$ Na Tabela 1 estão apresentados os resultados das análises física e química do solo após calagem.

Tabela 1: Resultado das análises físicas e químicas do solo utilizado para o preenchimento dos vasos plásticos.

\begin{tabular}{|l|l|l|l|}
\hline Características & Valores & Características & Valores \\
\hline $\begin{array}{l}\text { Densidade de partículas }\left(\mathrm{g} \mathrm{cm}^{-}\right. \\
\text {3) }\end{array}$ & 2,62 & $\mathrm{pH}$ & 7,01 \\
\hline Densidade do solo $\left(\mathrm{g} \mathrm{cm}^{-3}\right)$ & 1,41 & $\mathrm{~K}\left(\mathrm{mg} \mathrm{dm}^{-3}\right)$ & 150 \\
\hline Areia (\%) & 57,38 & $\mathrm{P}\left(\mathrm{mg} \mathrm{dm}^{-3}\right)$ & 56,86 \\
\hline Argila (\%) & 35,04 & $\mathrm{Ca}^{2+}\left(\mathrm{cmol}_{c} \mathrm{dm}^{-3}\right)$ & 11,6 \\
\hline Silte+Argila (\%) & $\mathrm{Mg}^{2+}\left(\mathrm{cmol}_{c} \mathrm{dm}^{-3}\right)$ & 6,1 \\
\hline $\mathrm{SB}\left(\mathrm{cmol}_{\mathrm{c}} \mathrm{dm}^{-3}\right)$ & $\mathrm{H}+\mathrm{Al}$ & 0,0 \\
\hline $\mathrm{t}\left(\mathrm{cmol}_{\mathrm{cm}} \mathrm{dm}^{-3}\right)$ & 18,1 & $\mathrm{Zn}\left(\mathrm{mg} \mathrm{dm}^{-3}\right)$ & 3,6 \\
\hline $\mathrm{T}\left(\mathrm{cmol}_{\mathrm{c}} \mathrm{dm}^{-3}\right)$ & 2,7 & $\mathrm{Fe}\left(\mathrm{mg} \mathrm{dm}^{-3}\right)$ & 95,8 \\
\hline $\mathrm{V}(\%)$ & $\mathrm{Mn}\left(\mathrm{mg} \mathrm{dm}^{-3}\right)$ & 17,0 \\
\hline $\mathrm{P}_{\mathrm{rem}}\left(\mathrm{mg} \mathrm{L}^{-1}\right)$ & 18,17 & $\mathrm{Cu}\left(\mathrm{mg} \mathrm{dm}^{-3}\right)$ & 2,15 \\
\hline $\mathrm{MO}\left(\mathrm{g} \mathrm{kg}^{-1}\right)^{\mathrm{b}}$ & 100,0 & & \\
\hline
\end{tabular}

Sendo: $\mathrm{pH}$ - potencial hidrogeniônico, em água 1:2,5; $\mathrm{P}$ - fósforo disponível; $\mathrm{K}$ - potássio trocável; $\mathrm{Ca}^{2+}$ - cálcio trocável; $\mathrm{Mg}^{2+}-$ magnésio trocável; $\mathrm{H}+\mathrm{Al}$ - acidez potencial; $\mathrm{Mn}$ - Manganês; $\mathrm{Cu}$-Cobre; SB - soma de bases; $\mathrm{t}$ - capacidade de troca catiônica efetiva; $\mathrm{T}$ - capacidade de troca catiônica a pH 7,0; V - índice de saturação por bases; P-rem - fósforo remanescente; $\mathrm{MO}$ - matéria orgânica; Zn - Zinco; Fe - Ferro.

Os tratamentos foram constituídos por testemunha (T1 - irrigação e adubação mineral recomendada para o eucalipto) e fertirrigação com água residuária da suinocultura (ARS), fornecendo-se 100 e $200 \%$ da dose de nitrogênio recomendada para a cultura do eucalipto sem adubação mineral complementar (T2 e T4) e com adubação mineral complementar (T3 e T5), respectivamente, sendo conduzido no delineamento inteiramente ao acaso, com cinco tratamentos e cinco repetições.

A água residuária utilizada nas fertirrigações foi obtida no Setor de Suinocultura do IFGoiano, após passagem pelas grades e esterqueira (tratamento preliminar). Para fins de caracterização do efluente, foram analisadas, conforme metodologias recomendadas pela APHA (2012), as seguintes características: pH, turbidez, teores totais de fósforo $(\mathrm{P})$, potássio $(\mathrm{K})$, nitrogênio $(\mathrm{N})$, sódio $(\mathrm{Na})$ e amônio, condutividade elétrica (CE), sólidos totais (ST) e demanda química de oxigênio (DQO), cujos resultados estão apresentados na Tabela 2.

Tabela 2: Caracterização da água residuária da suinocultura utilizada nos ensaios experimentais.

\begin{tabular}{|l|l|l|l|}
\hline Características & valores & Características & valores \\
\hline $\mathrm{pH}$ & 7,46 & $\mathrm{P}_{\mathrm{T}}\left(\mathrm{mg} \mathrm{L}^{-1}\right)$ & 159,34 \\
\hline Turbidez (UNT) & 560,00 & $\mathrm{~K}_{\mathrm{T}}\left(\mathrm{mg} \mathrm{L}^{-1}\right)$ & 663,19 \\
\hline $\mathrm{CE}\left(\mu \mathrm{S} \mathrm{cm}^{-1}\right)$ & $\mathrm{Na}\left(\mathrm{mg} \mathrm{L}^{-1}\right)$ & 127,25 \\
\hline Amônio $\left(\mathrm{mg} \mathrm{L}^{-1}\right)$ & $6.490,00$ & $\mathrm{ST}\left(\mathrm{mg} \mathrm{L}^{-1}\right)$ & $6.579,00$ \\
\hline $\mathrm{N}_{\mathrm{T}}\left(\mathrm{mg} \mathrm{L}^{-1}\right)$ & 1,35 & $\mathrm{DQO}\left(\mathrm{mg} \mathrm{O}_{2} \mathrm{~L}^{-1}\right)$ & $9.996,00$ \\
\hline
\end{tabular}


Para o cálculo da lâmina de ARS a ser aplicada na fertirrigação do eucalipto, utilizou-se a Equação 1, recomendada pela EPA (1981), baseando-se na concentração de nitrogênio, por apresentar maior concentração relativa.

$$
\mathrm{L}_{\mathrm{w}}=\frac{\mathrm{C}_{\mathrm{p}}(\mathrm{PR}-\mathrm{ET})+10 \mathrm{U}}{(1-\mathrm{f}) \mathrm{C}_{\mathrm{n}}-\mathrm{C}_{\mathrm{p}}}
$$

Em que:

$\mathrm{L}_{\mathrm{w}}$ - lâmina de aplicação anual, $\mathrm{cm}_{\text {ano }}{ }^{-1}$; $\mathrm{Cp}$ - concentração de nitrogênio na água de percolação, $\mathrm{mg} \mathrm{L}^{-1}$; $\mathrm{PR}$ - precipitação local, $\mathrm{cm} \mathrm{ano}^{-1}$;

ET - evapotranspiração da cultura no local, $\mathrm{cm}^{-1} \mathrm{ano}^{-1}$; $\mathrm{U}$ - absorção de nitrogênio pela cultura, $\mathrm{kg} \mathrm{ha}^{-1} \mathrm{ano}^{-1}$; $\mathrm{Cn}$ - concentração de nitrogênio na água residuária, $\mathrm{mg} \mathrm{L}^{-1} ; \mathrm{e}$ $f$ - fração do nitrogênio que é removido por desnitrificação e volatilização, adimensional.

Este método objetiva evitar a contaminação das águas subterrâneas com nitrato em níveis acima dos aceitáveis (10 mg L L ${ }^{-1}$. Para o cálculo das dosagens, considerou-se $\mathrm{Cp}$ como $10 \mathrm{mg} \mathrm{L}^{-1}$ conforme CONAMA 357/2005 (BRASIL, 2005), PR-ET (obtido com auxílio de estação meteorológica automática), U igual a $100 \mathrm{~kg}$ $h^{-1}$ (CFSEMG, 1999), f igual a 20\% (MATOS, 2016) e Cn obtida em avaliações quinzenais. As aplicações seguiram a exigência nutricional do eucalipto quanto à adubação de cobertura, conforme sugerida por Gonçalves et al. (1996).

A adubação mineral complementar foi calculada subtraindo-se dos valores de $\mathrm{P}$ e $\mathrm{K}$ recomendados por CFSEMG (1999), a quantidade aportada destes nutrientes advindos das diferentes doses de ARS aplicadas. Dessa forma, foram adicionados 22,6 e $11,3 \mathrm{~g} \mathrm{cova}^{-1}$ de supersimples e, 11,8 e 5,9 $\mathrm{g} \mathrm{cova}^{-1}$ de cloreto de potássio, aos solos submetidos aos tratamentos 3 e 5, respectivamente. Tanto a adubação mineral, quanto as lâminas de fertirrigações foram aplicadas em parcelas quinzenais conforme recomendações da CFSEMG (1999), sendo finalizada aos 70 dias após o transplantio.

As mudas de eucalipto foram irrigadas diariamente repondo-se a demanda evapotranspirométrica, determinada por meio de uma estação meteorológica automática e utilizando-se a metodologia proposta por Doorenbos et al. (1977) e modificada por Mantovani (2002). A lâmina diária foi parcelada em três vezes e aplicada nos horários de 7, 13 e 16 horas por microaspersores.

Para analisar o desenvolvimento das mudas foram determinadas a altura $(\mathrm{H})$ e o diâmetro do coleto (DC) das mudas de eucalipto. Aos 110 dias após o transplantio (DAT), todas as plantas foram retiradas, tendo suas partes separadas em folhas, raiz e coleto, que foram utilizadas para determinação da matéria seca da parte aérea (MSPA), da massa seca da raiz (MSR) e da massa seca total (MST). O padrão de qualidade das mudas produzidas foi determinado através do índice de qualidade de Dickson (IQD) obtido conforme Equação 2 (DICKSON et al.,1960, citado por CALDEIRA et al., 2013).

$$
\mathrm{IQD}=\left(\frac{\mathrm{MST}}{\frac{\mathrm{H}}{\mathrm{DC}}+\frac{\mathrm{MSPA}}{\mathrm{MSR}}}\right)
$$


Os dados foram submetidos à análise de variância, teste de média e análise de regressão, adotandose um nível de até $5 \%$ de probabilidade. Os modelos de regressão foram escolhidos com base na significância dos coeficientes de regressão, utilizando-se o teste t num nível de até $10 \%$, no coeficiente de determinação e no processo em estudo.

\section{RESULTADOS}

Na Figura 1 estão apresentas as curvas ajustadas das variáveis relacionadas ao desenvolvimento das mudas de eucalipto em função do tempo, para os diferentes tratamentos avaliados.

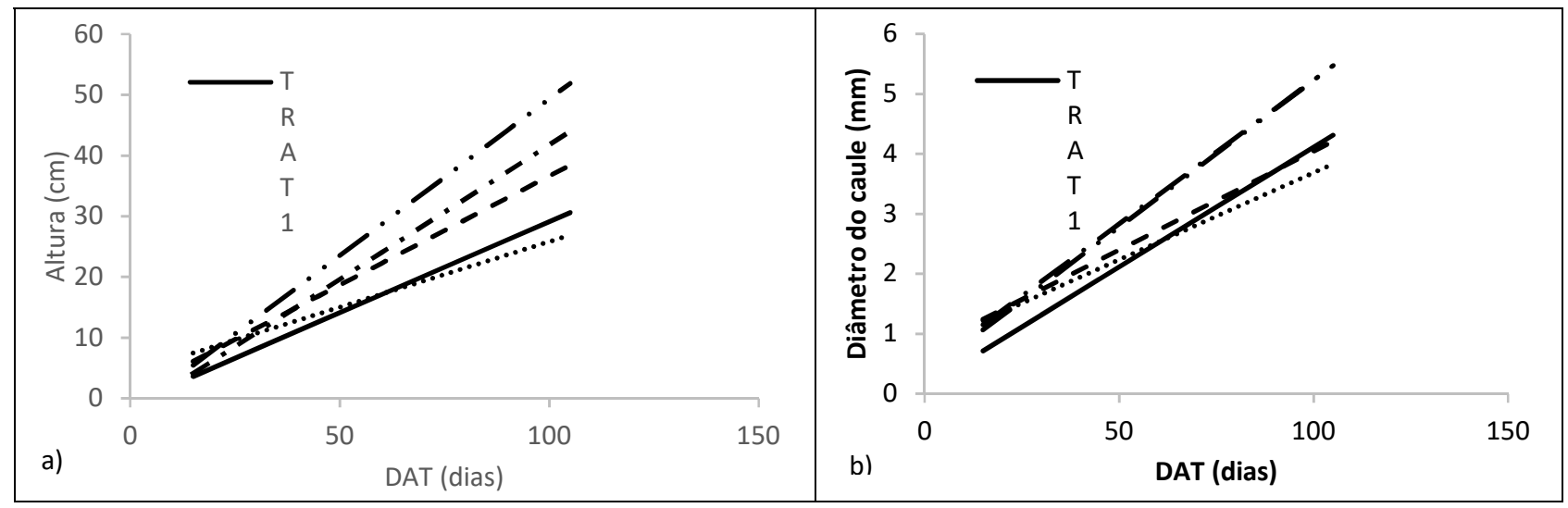

Figura 1: Curvas ajustadas relacionadas ao desenvolvimento das mudas de eucalipto em função do tempo, para os diferentes tratamentos: (a) altura e (b) diâmetro do coleto.

Na Tabela 3 estão apresentados os valores das massas secas (porcentagens do total, em base seca) nos diferentes órgãos das mudas de eucalipto, bem como o índice de qualidade de Dickson (IQD).

Tabela 3: Valores da matéria seca (base seca) nos diferentes órgãos das mudas de eucalipto, índice de qualidade de Dickson (IQD) e, respectivos testes de média.

\begin{tabular}{|l|l|l|l|l|}
\hline \multirow{2}{*}{ Tratamentos } & \multicolumn{2}{|l|}{ Umidade } & IQD \\
\cline { 2 - 5 } & Raiz (\%) & Folha (\%) & Coleto (\%) \\
\hline T1 & $23,59 \mathrm{~B}$ & $44,79 \mathrm{C}$ & $31,62 \mathrm{D}$ & $0,53 \mathrm{C}$ \\
\hline T2 & $25,33 \mathrm{~A}$ & $45,06 \mathrm{E}$ & $31,94 \mathrm{C}$ & $0,45 \mathrm{E}$ \\
\hline T3 & $23,23 \mathrm{~B}$ & $43,28 \mathrm{D}$ & $33,49 \mathrm{~B}$ & $0,49 \mathrm{D}$ \\
\hline T4 & $20,48 \mathrm{D}$ & $43,90 \mathrm{~B}$ & $35,62 \mathrm{~A}$ & $0,78 \mathrm{~A}$ \\
\hline T5 & $21,74 \mathrm{C}$ & $47,67 \mathrm{~A}$ & $30,60 \mathrm{E}$ & $0,71 \mathrm{~B}$ \\
\hline
\end{tabular}

${ }^{*}$ Médias seguidas por pelo menos uma mesma letra maiúscula nas colunas indicam que os tratamentos avaliados, não diferem entre si, a $5 \%$ de probabilidade, pelo teste Tukey.

\section{DISCUSSÃO}

Verifica-se, na Figura 1a, que as mudas submetidas aos tratamentos com aplicações de ARS apresentaram os maiores valores de alturas em relação às plantas submetidas ao Tratamento 1 (testemunha). Tal fato pode estar relacionado com a forma de disponibilização dos nutrientes às plantas, uma vez que na adubação mineral (Tratamento 1) os nutrientes estão prontos para serem assimilados, enquanto nas fertirrigações, estes nutrientes só estarão disponíveis após mineralização dos compostos orgânicos presentes na água residuária.

Estes resultados estão de acordo com aqueles apresentados por Eckhardt (2015), Toledo et al. (2015), Batista et al. (2014) e Andrade et al. (2006), onde a adubação orgânica resultou em melhores 
desenvolvimento às plantas. Segundo Eckhardt (2015), diferentemente dos fertilizantes minerais, que são solúveis e disponibilizam os nutrientes assim que adicionados ao solo, nos fertilizantes orgânicos os nutrientes estão presentes predominantemente na forma orgânica e necessitam passar pelo processo de mineralização para que possam ficar disponíveis na solução do solo e assim disponibilizados para as plantas.

Dessa forma, ao utilizar a ARS como fonte de nutrientes, seria reduzido o processo de percolação ou volatização dos nutrientes quando comparado com a adubação química. Consequentemente, o aumento da dose de ARS permitirá que uma maior quantidade de nutriente seja disponibilizada para as plantas, e assim favorecendo o crescimento se comparada com a testemunha.

As plantas submetidas aos Tratamentos 4 e 5 apresentaram os melhores resultados de altura, sendo estes fertirrigados com a mesma lâmina de ARS (fornecimento de $200 \%$ do nitrogênio requerido). Coelho et al. (2017) trabalhando com Corymbia citriodora observaram comportamento semelhante, onde a aplicação de ARS com a dose de $200 \%$ resultou em maiores valores de altura das plantas. Do mesmo modo, Pelissari et al. (2009) e Batista et al. (2014) verificaram que a fertirrigação com ARS proporcionou bom desenvolvimento das mudas de eucalipto com ênfase em suas alturas.

Observa-se, na Figura 1b, que as plantas submetidas ao Tratamento Testemunha (T1) e aquelas fertirrigadas com ARS fornecendo 100\% da dose de nitrogênio às plantas (T2 e T3) apresentaram os menores valores do diâmetro de coleto ao longo do período experimental e, estatisticamente, não diferiram entre si. Assim, da mesma forma que observado com a variável altura de plantas, verificou-se, também, que as plantas submetidas às maiores doses de ARS apresentaram os maiores diâmetros de coleto.

Estes resultados estão de acordo com diversos estudos em que maiores dosagens de ARS proporcionaram os melhores desenvolvimentos das plantas, dentre eles, pode se citar os trabalhos de Coelho et al. (2017), Batista et al. (2014), Souza et al. (2013), Souza et al. (2010) e Pelissari et al. (2009). Observa-se, na tabela 3, que as fertirrigações com ARS proporcionaram maiores porcentagens de matéria seca nos diferentes órgãos, quando comparadas com as plantas submetidas ao Tratamento Testemunha (T1). Verificase, ainda, que incrementos nas doses de ARS resultaram em maiores percentuais de matéria seca na folha.

Este fato pode estar relacionado com a maior disponibilidade de nitrogênio às plantas, uma vez que, na forma mineral há grandes perdas por volatilização ou lixiviação (CABEZAS et al., 2008), enquanto incrementos das doses de ARS proporcionam aumento no teor de nitrogênio orgânico, ficando disponível por mais tempo e em maiores quantidades (BONI et al., 2015; TRONI et al., 2013). Dessa forma, a maior presença de nitrogênio proporciona maior concentração de fotossintatos e, consequentemente, maior desenvolvimento das plantas (SILVA, 2013).

De acordo com Kozlowski et al. (1991), o crescimento inicial das plantas no campo depende de fotossintatos armazenados pela muda. O maior acúmulo de fotossintatos ocorre na parte aérea da muda. Em contrapartida, quando alguns nutrientes limitam o crescimento vegetal, como o $\mathrm{N}$ e o $\mathrm{P}$, as raízes transformam-se em um forte dreno de carboidratos, causando, assim, maior limitação ao crescimento da parte aérea do que da raiz (ARAÚJO et al., 2006). Ainda segundo estes autores, o acúmulo de biomassa é 
uma característica importante relacionada ao crescimento da planta, quanto maior o valor da matéria seca total, melhor a qualidade da muda.

O IQD é considerado como um bom indicador de qualidade de mudas porque são utilizados para seu cálculo a robustez (relação H/DC) e o equilíbrio da distribuição da biomassa (relação MSPA/MSR) (ELLOY et al., 2013; CALDEIRA et al., 2013; BINOTTO et al., 2010). Em relação aos valores de IQD (Tabela 3), verifica-se que os valores obtidos neste estudo são superiores a diversos valores apresentados na literatura, tais como os trabalhos de Gomes et al. (2017), Batista et al. (2014), Eloy et al., (2013) e, também, são superiores àqueles considerados como mínimo para mudas de qualidade segundo Binotto et al. (2010), Gomes et al., (2002), que é de 0,20, indicando a qualidade das mudas produzidas. De acordo com Caldeira et al. (2013), quanto maior o índice, maiores as chances de sobrevivência das mudas em campo.

Verifica-se, ainda na Tabela 3, que incrementos nas doses de ARS proporcionaram aumentos nos valores de IQD, sendo que as plantas submetidas aos tratamentos com dosagens de ARS fornecendo $100 \%$ do nitrogênio (T2 e T3) apresentaram valores inferiores àqueles obtidos pelas plantas submetidas ao Tratamento Testemunha (T1). Observa-se, também, que o fornecimento de nitrogênio via ARS, nas dosagens de $200 \%$ do recomendado para o eucalipto, produziu mudas com os maiores valores de IQD, contribuindo para a formação de mudas de melhor qualidade, apresentando maiores, diâmetros de coleto (conforme Tabela 2) e matéria seca na parte aérea (conforme Tabela 3).

Analisando os resultados apresentados, verifica-se que a fertirrigação com ARS fornecendo $200 \%$ da dose de nitrogênio recomendada, produziu mudas de eucalipto com qualidade superiores àquelas produzidas com adubação mineral, suprindo as demandas nutricionais da cultura. Tendo-se em vista os custos de produção, a fertirrigação com ARS fornecendo $200 \%$ da dose de nitrogênio, sem complementação da adubação, passa a ser uma recomendação técnica e ambientalmente adequada.

\section{CONCLUSÕES}

A fertirrigação com água residuária da suinocultura (ARS) supriu as demandas nutricionais das mudas de eucalipto proporcionando mudas de eucalipto com maiores comprimentos, diâmetros do coleto e índice de qualidade. A fertirrigação com ARS fornecendo 200\% da dose de nitrogênio recomendada para a cultura do eucalipto sem complementação da adubação passa a ser uma recomendação técnica e ambientalmente mais adequada.

\section{REFERÊNCIAS}

ANDRADE, G. C.; BELLOTE, A. F. J.; SILVA, H. D.; DEDECK, R. A.; GAVA, J. L.. Efeitos da aplicação de lixo urbano compostado na produtividade de eucalyptus grandis. Boletim Pesquisa Florestal, Colombo, n.53, p.39-66, 2006.

APHA. American Public Health Association. Standard methods for the examination of water and wastewater. 22 ed. New York: APHA; AWWA; WPCR, 2012.
ARAÚJO, A. P.; MACHADO, C. T. T.. Fósforo. In: FERNANDES, M. S.. Nutrição mineral de plantas. Viçosa: Sociedade Brasileira de Ciência do Solo, 2006. p.253-280.

ABRAF. Associação Brasileira de Produtores de Florestas Plantadas. Anuário estatístico da ABRAF 2012: ano base 2011. Brasília: ABRAF, 2012.

BATISTA, R. O.; MARTINEZ, M. A.; PAIVA, H. N.; BATISTA, R. O.; CECON, P. R.. Efeito da água residuária da suinocultura no desenvolvimento e qualidade de mudas de Eucalyptus 
urophylla. Ciência Florestal, Santa Maria, v.24, n.1, p.127135, 2014. DOI: http://dx.doi.org/10.5902/1980509813330

BINOTTO, A. F.; LÚCIO, A. D.; LOPES, S. J.. Correlations between growth variables and the Dickson quality index in forest seedlings. Revista Cerne, Lavras, v.16, n.4, p.457-464, 2010. DOI: http://dx.doi.org/10.1590/S010477602010000400005

BLANCO, F. F.. Tolerância do tomateiro a salinidade sob fertirrigação e calibração de medidores de íons específicos para determinação de nutrientes na solução e na planta. Tese (Doutorado em Agronomia) - Escola Superior de Agricultura Luiz de Queiroz(ESALQ), Piracicaba, 2004.

BONINI, C. S.; ALVES, M. C.; MONTANARI, R.. Lodo de esgoto e adubação mineral na recuperação de atributos químicos de solo degradado. Revista Brasileira de Engenharia Agrícola e Ambiental, v.19, n.4, p.388-393, 2015. DOI: http://dx.doi.org/10.1590/1807-1929/agriambi.v19n4p388$\underline{393}$

BRASIL. Resolução CONAMA no 357/2005: Dispõe sobre a classificação dos corpos de água e diretrizes ambientais para o seu enquadramento, bem como estabelece as condições e padrões de lançamento de efluentes, e dá outras providências. Brasília: DOU, 2005.

CABEZAS, W. A. R. L.; SOUZA, M. A.. Volatilização de amônia, lixiviação de nitrogênio e produtividade de milho em resposta à aplicação de misturas de uréia com sulfato de amônio ou com gesso agrícola Ammonia volatilization, leaching of nitrogen and corn yield in response to the application of mix of urea and ammonium sulphate or gypsum. Revista Brasileira de Ciência do Solo, v.32, n.6, p.2331-2342, 2008. DOI: http://dx.doi.org/10.1590/S0100$\underline{06832008000600012}$

CABRAL, J. R.; FREITAS, P. S. L.; REZENDE, R.; MUNIZ, A. S.; BERTONHA, A.. Impacto da água residuária de suinocultura no solo e na produção de capim-elefante. Revista Brasileira de Engenharia Agrícola e Ambiental, Campina Grande, v.15, n. 8, p.824-831, 2011.

CALDEIRA, M. V. W.; DELARMELINA, W. M.; FARIA, J. C. T; JUVANHO, R. S.. Substratos alternativos na produção de mudas de Chamaecrista desvauxii. Revista Árvore, v.37, n.1, p.31-39, 2013. DOI: http://dx.doi.org/10.1590/S0100$\underline{67622013000100004}$

CFSEMG. Comissão de Fertilidade do Solo do Estado de Minas Gerais. 5a aproximação: Recomendações para o uso de corretivos e fertilizantes em Minas Gerais. Viçosa, 1999.

COELHO, J. A. S.; VIEIRA, C. R.; WEBER, O. L. S.. Growth and nutrition of Corymbia citriodora seedlings using doses of liquid swine waste. Comunicata Scientiae v.8, n.2, p.256264, 2017. DOI: http://doi.org/10.14295/CS.v8i2.1851

DOBLINSKI A, F.; SAMPAIO, S. C.; SILVA, V. R.; NÓBREGA, L. H. P.; GOMES, S. D.; DAL BOSCO, T. C.. Nonpoint source pollution by swine farming wastewater in bean crop. Revista Brasileira Engenharia Agrícola e Ambiental, Campina Grande, v.14, n.1, p.87-93, 2010.

ECKHARDT, D. P.. Fertilizantes orgânicos: índice de eficiência e produção de alface, cenoura e mudas de eucalipto. Tese
(Doutorado em Ciência do Solo) - Universidade Federal de Santa Maria, Santa Maria, 2015.

ELOY, E.; CARON, B. O.; SCHMIDT, D.; BEHLING, A.; SCHWERS, L.; ELLI, E. F.. Avaliação da qualidade de mudas de Eucalyptus grandis utilizando parâmetros morfológicos. Revista Floresta, Curitiba, v.43, n.3, p.373-384, 2013. DOI: http://dx.doi.org/10.5380/rf.v43i3.26809

EPA. Environmental Protection Agency. Process design manual: land treatment of municipal wastewater. Washington: Department of the interior, 1981.

GOMES, J. M.. Parâmetros morfológicos na avaliação de mudas de Eucalyptus grandis, produzidas em diferentes tamanhos de tubetes e dosagens de N-P-K. Tese (Doutorado em Ciência Florestal) - Universidade Federal de Viçosa, Viçosa, 2001.

GOMES, J. M.; COUTO, L.; LEITE, H. G.; XAVIER, A.; GARCIA, S. L. R.. Parâmetros morfológicos na avaliação da qualidade de mudas de Eucalyptus grandis. Revista Árvore, Viçosa, v.26, n.6, p.655-664, 2002.

GONÇALVES, J. L. M.; POGGIANI, F.. Substratos para produção de mudas florestais. In: CONGRESSO LATINO AMERICANO DE CIÊNCIA DO SOLO, 13. Anais. Águas de Lindóia: USP/ESALQ/ SBCS/CEA/SLACS/SBM, 1996.

GUERREIRO, C. A.; COLLI JÚNIOR, G.. Controle de qualidade de mudas de Eucalyptus spp. na Champion Papel e Celulose S.A. In: SIMPÓSIO INTERNACIONAL DE MÉTODOS DE PRODUÇÃO E CONTROLE DE QUALIDADE DE SEMENTES E MUDAS FLORESTAIS. Anais. Curitiba: UFPR/FUPEF, 1984.

IBGE. Instituto Brasileiro de Geografia e Estatística. Abate de animais, produção de leite, couro e ovos. 2016.

JANG, T. I.; KIM, H. K.; SEONG, C. H; LEE, E. J.; PARK, S. W. Assessing nutrient losses of reclaimed wastewater irrigation in paddy fields for sustainable agriculture. Agricultural Water Management, v.104, p.235-243, 2012. DOI: http://dx.doi.org/10.1016/j.agwat.2011.12.022

KOZLOWSKI, T. T.; KRAMER, P. J.; PALLARDY, S. G.. The physiological ecology of woody plants. New York: Academic Press, 1991.

MA, D.; JIANG, Z.; LAY, C.; ZHOU, D.. Electricity generation from swine wastewater in microbial fuel cell: Hydraulic reaction time effect. International Journal of Hydrogen Energy, v.41, n.46, p.21820-21826, 2016. DOI: http://doi.org/10.1016/j.ijhydene.2016.08.019

MAGGI, C. F.; FREITAS, P. S. L.; SAMPAIO, S. C.; DIETER, J.. Impacts of the application of swine wastewater in percolate and in soil cultivated with soybean. Engenharia Agrícola Jaboticabal, v.33, n.2, p.279-290, 2013. DOI: http://dx.doi.org/10.1590/S0100-69162013000200007

MATOS, A. T.; MATOS, M. P.. Disposição de águas residuárias no solo e em sistemas alagados construídos. Viçosa: UFV, 2016.

PELISSARI, R. A. Z.; SAMPAIO, S. C.; GOMES, S. D.; CREPALLI, M. D. A. S.. Lodo têxtil e água residuária da suinocultura na produção de mudas de Eucalyptus grandis (W, Hill ex 
Maiden). Engenharia Agrícola, Jaboticabal, v.29, n.2, p.288300, 2009.

ROCHA, J. H. T.; PIETRO, M. R.; BORELLI, K.; BACKES, C.; NEVES, M. B.. Produção e desenvolvimento de mudas de eucalipto em função de doses de fósforo. CERNE, Lavras, v.19, n.4, p.535-543, 2013.

SANTOS, J. S.; LIMA, V. L. A.; BORGES JÚNIOR, J. C. F.; SILVA, L. V. B. D.; AZEVEDO, C. A. V.. Mobilidade de solutos em colunas de solo com água residuária doméstica e de suinocultura. Revista Brasileira de Engenharia Agrícola e Ambiental, Campina Grande, v.14, n.11, p.1226-1233, 2010.

SILVA, A. A. F.; SOUZA, J. A. R; CARVALHO, W. B.; MENDONÇA, R. B.; MOREIRA, D. A.. Distribuição da umidade do solo num sistema irrigado por gotejamento superficial com diferentes inclinações do terreno. REVENG Engenharia na agricultura, Viçosa , v.23, n.3. p261-269, 2015.

SILVA, G. S. P.. Concentração de amido e estimativa de rendimento de álcool em batata-doce cultivada com diferentes fontes e doses de potássio. Dissertação (Mestrado em Bioenergia) - Universidade Estadual do Centro-Oeste, Guarapuava, 2013.
SOUZA, J. A.; MOREIRA, D. A.; MARTINS, I. P.; CARVALHO, C. V. M.; CARVALHO, W. B.. Sanidade de frutos de pimentão fertirrigados com água residuária da suinocultura. Ambiente \& Água-An Interdisciplinary Journal of Applied Science, v.8, n.2, p.124-134, 2013. DOI: http://dx.doi.org/10.4136/ambiagua. 1115

SOUZA, J. A. R.; MOREIRA, D. A.; COLEHO, D. F.. Crescimento e desenvolvimento de tomateiro fertirrigado com água residuária da suinocultura. Revista Ambiente \& Água, v.5, n.2, p.144-157, 2010. DOI: http://doi.org/10.4136/ambiagua.144

TOLEDO, F. H.; VENTURIN, N. L. C.; DIAS, B. A., VENTURIN, R. P.; MACEDO, R. L.. Composto de resíduos da fabricação de papel e celulose na produção de mudas de eucalipto.

Revista Brasileira Engenharia Agrícola Ambiental, v.19, n.7, p.711-716, 2015. DOI: http://dx.doi.org/10.1590/18071929/agriambi.v19n7p711-716

TRANI, P. E.; TERRA, M. M.; TECCHIO, M. A.; TEIXEIRA, L. A. J.; HANASIRO, J.. Adubação orgânica de hortaliças e frutíferas. Informações Tecnológicas. Campinas: IAC, 2013

USDA. United States Department of Agriculture. Livestock and Poultry: World Markets and Trade. Foreign Agricultural Service. 2016.

A CBPC - Companhia Brasileira de Produção Científica (CNPJ: 11.221.422/0001-03) detém os direitos materiais desta publicação. Os direitos referem-se à publicação do trabalho em qualquer parte do mundo, incluindo os direitos às renovações, expansões e disseminações da contribuição, bem como outros direitos subsidiários. Todos os trabalhos publicados eletronicamente poderão posteriormente ser publicados em coletâneas impressas sob coordenação da Sustenere Publishing, da Companhia Brasileira de Produção Científica e seus parceiros autorizados. Os (as) autores (as) preservam os direitos autorais, mas não têm permissão para a publicação da contribuição em outro meio, impresso ou digital, em português ou em tradução. 